\title{
Histopathology Images
}

\section{Melanoma}

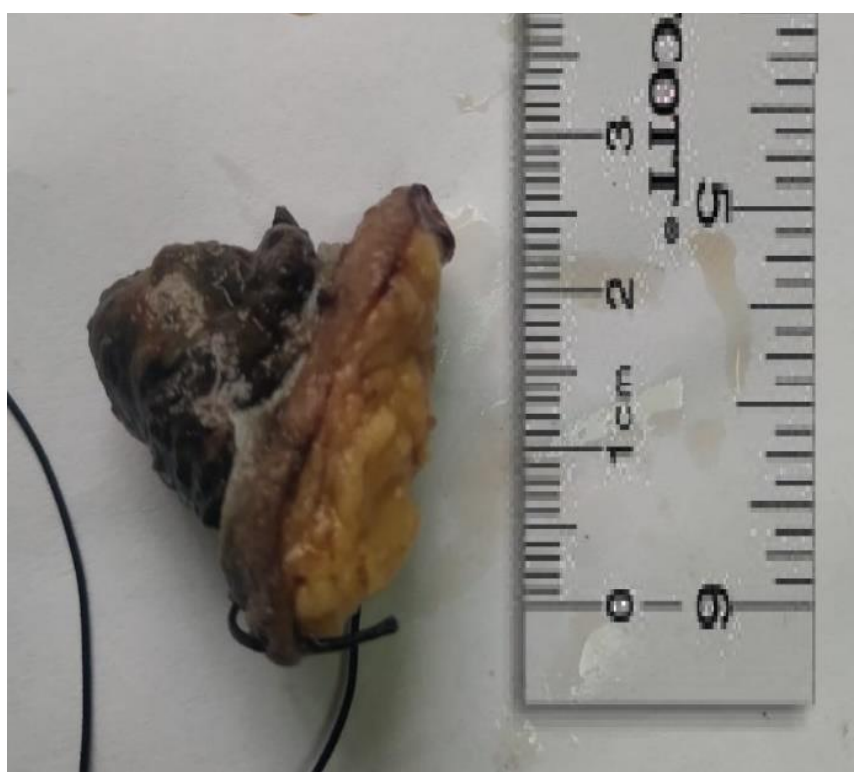

Figure 1: Gross appearance of Melanoma. Skin with large protruded pigmented lesion measuring approximately $2 \mathrm{~cm}$ in high.

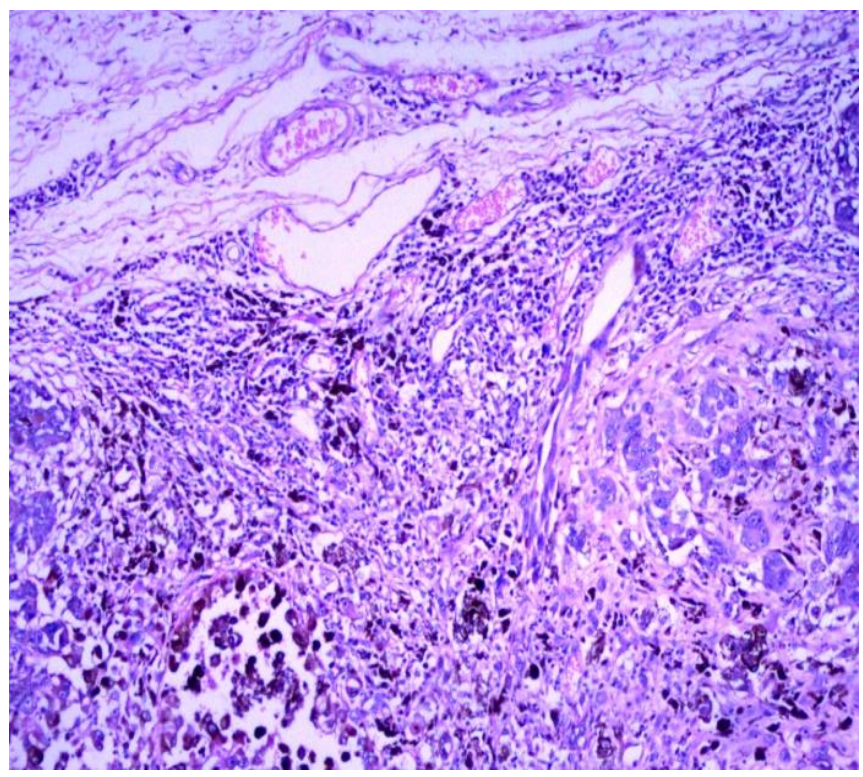

Figure 3: Nest of Melanotic cells with melanin.

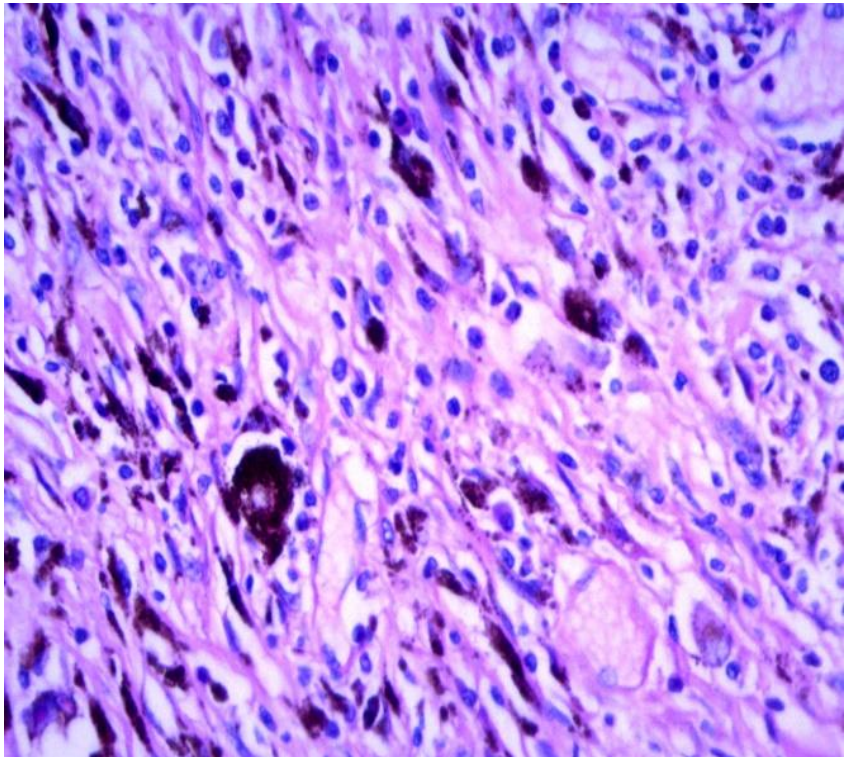

Figure 2: Microscopic view of melanoma cell nest with abundant melanin. The cells appear markedly pleomorphic (H\&E 400).

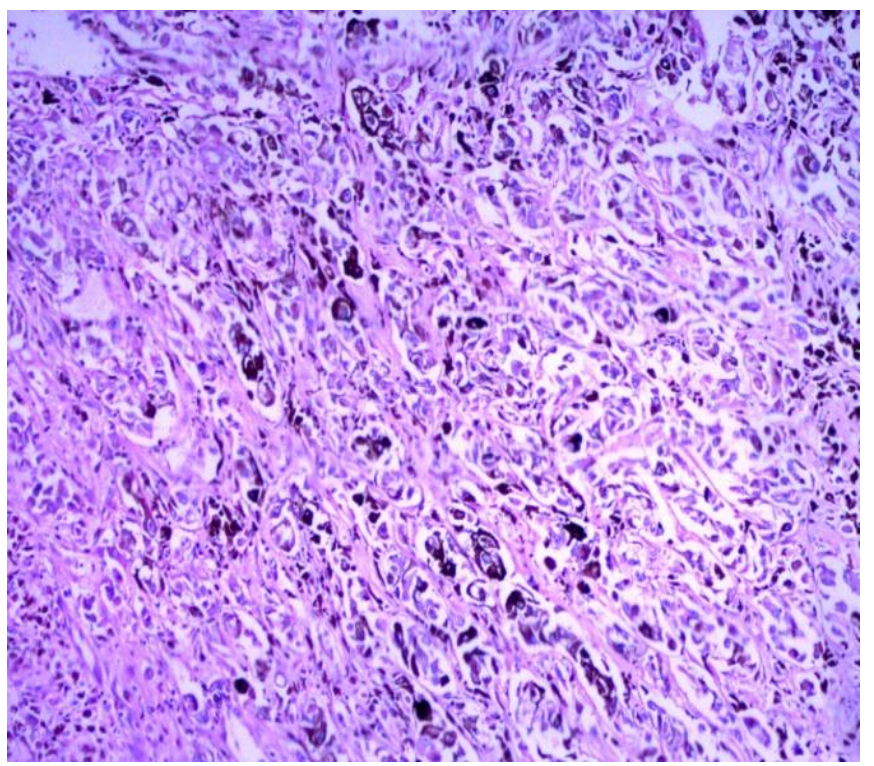

Figure 4: High power microscopic view showing nest of melanotic cells with blackish melanin pigmentation. 


\section{Polypoidal Leiomyoma}

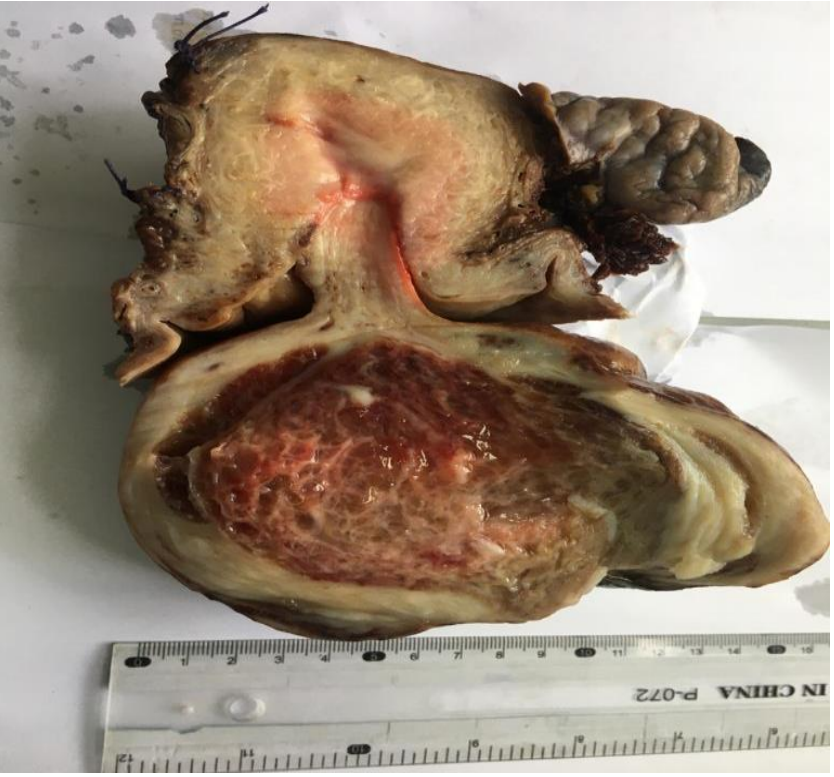

Figure 1: Cut surface of leiomyoma with myxoid degeneration.

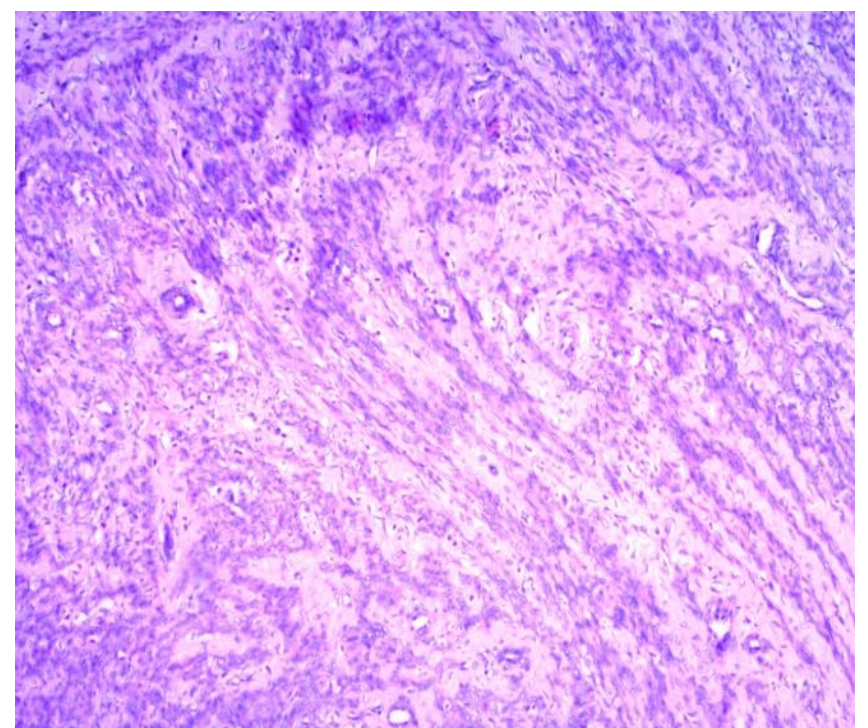

Figure 3: Microscopic view. Fascicles of smooth muscles cells with myxoid stroma (H\&E 100).

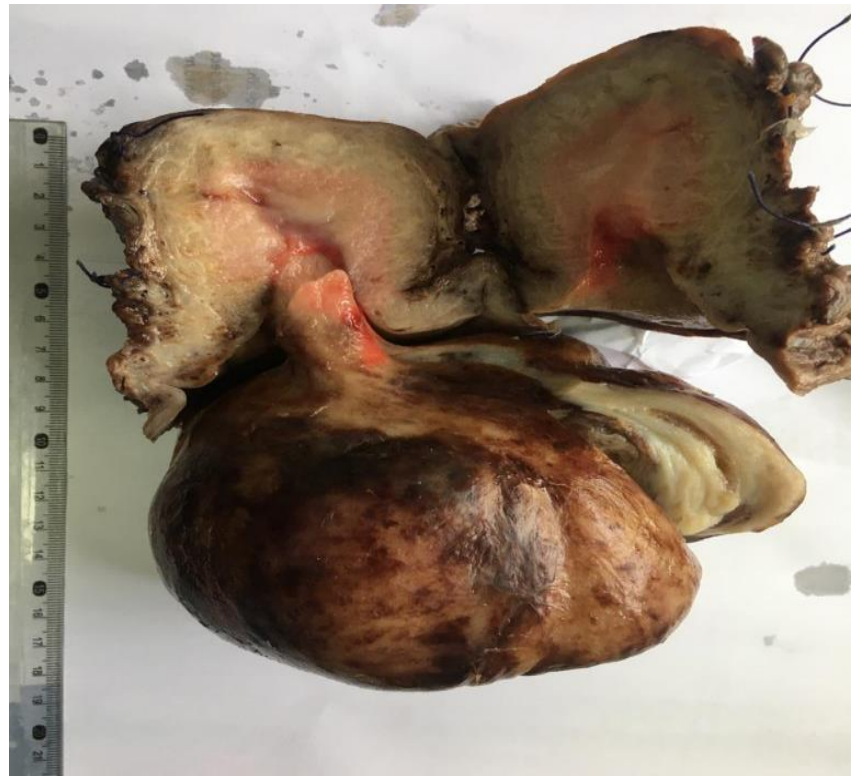

Figure 2: Large polypoid leiomyoma hanging from the cervical cavity.

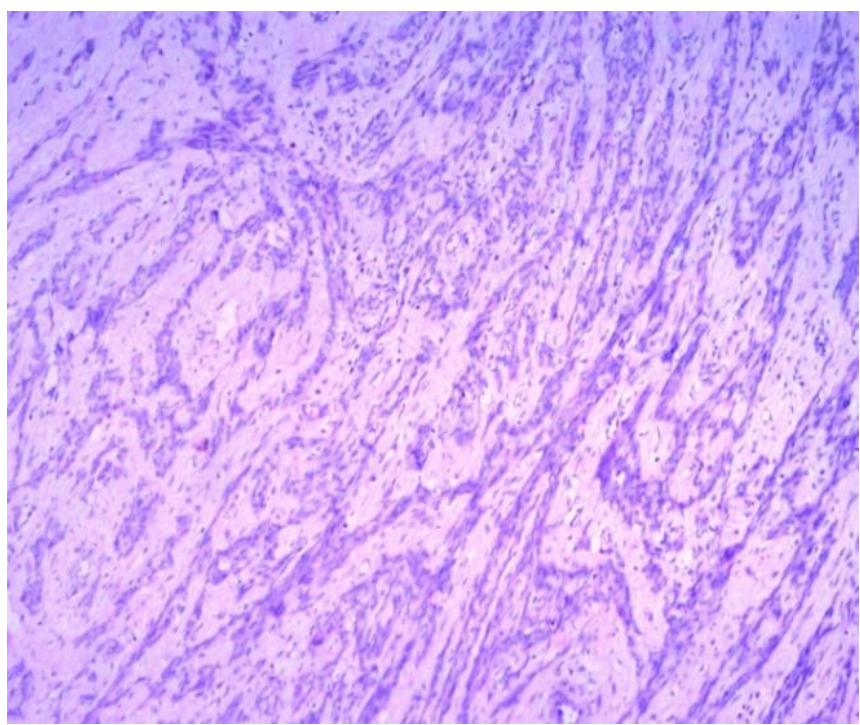

Figure 4: Fascicles of smooth muscles with bland looking cells and myxoid areas (H\&E 100).

\section{Contributed by:}

Prof Dr. Saeed Alam, Dr. Javeria Faridi

Department of Pathology, Islamabad Medical \& Dental College 